\title{
Spirometry testing education in medical schools: a missed opportunity?
}

\author{
Barbara P. Yawn ${ }^{a, *}$, Roy A. Yawn ${ }^{b, 1}$ \\ a Department of Family and Community Health, University of Minnesota, Minneapolis, Minnesota, USA \\ b Department of Internal Medicine, Olmsted Medical Center, 210 9th Street SE, Rochester, Minnesota, \\ USA
}

Received 29 October 2004; accepted 31 October 2004

Obstructive lung diseases, primarily asthma and COPD, are common [1-5] and are often present in patients seen by physicians of all specialties. The prevalence of asthma in children and adults has been increasing over the past 15 years and varies between $5 \%$ and $15 \%$ in both industrialized and developing nations of the world [1,6-10]. COPD is the fourth leading cause of adult mortality and is projected to become the third leading cause by 2020 [1]. Both asthma and COPD are most accurately diagnosed using simple office-based spirometry testing. Spirometry testing is also recommended for monitoring the course and progression of both asthma and COPD [10-15].

The performance and interpretation of spirometry testing is not a routine component of medical education for medical students and residents in many parts of the industrialized world [16-20]. A search of the medical education

\footnotetext{
* Corresponding author. Tel.: +1 507287 2758; fax: +1507 2872722 .

E-mail addresses: yawnx002@umn.edu (B.P. Yawn), ryawn@olmmed.org (R.A. Yawn).

1 Tel.: +1 5072883443 .
}

literature since the 1970s reveals few papers discussing the inclusion of pulmonary function testing in curricula for student physicians $[16,18,21]$. Japanese researchers found that several Japanese medical schools had short presentations on spirometry testing, but only three allowed sufficient time to permit the students to participate in spirometry testing or to practice interpreting the test results [16]. Most curricular content incorporates lectures that present normal and abnormal spirometry curves during discussions of pulmonary physiology and pathophysiology. Any additional instruction tends to occur following chance encounters between students and patients with COPD or asthma, during hospital-based or emergency department rotations or in outpatient clinics that perform spirometry testing and use the results for clinical decision-making [16].

Conversely, there are several recently-published articles regarding the best methods for educating medical students about the interpretation of electrocardiograms (ECGs) [22-24]. Whilst the ECG is a basic test for the diagnosis of acute coronary syndromes and myocardial infarction, it is not very useful for the diagnosis of coronary 
artery disease in the general population and is no longer recommended as a routine screening test for adults. The ECG is an important office-based test but it is certainly no more useful than spirometry testing for diagnosing common conditions in the ambulatory setting.

Education on ECG interpretation provides a pertinent example of how to teach medical students to interpret the results of an important office-based test. Hurst [23] suggested that wave-form pattern recognition is an excellent initial approach to ECG education. Spirometry lends itself well to a similar approach because the flow-volume loops or expiratory curves can also be interpreted on the basis of a wave-form method. Nathanson et al. [24] have used and compared web-based and didactic presentations and found similar success rates with knowledge acquisition when the wave-form approach was used.

Until recently the recommended content of the medical school curriculum was outlined in broad strokes, allowing teachers, lecturers and invited speakers wide latitude in specific topic selection based on their interests and expertise [25]. The popular case-based learning method is often highly dependent on the local faculty for the selection of specific cases and their clinical content. At this time in the United States, the concept of core competencies has become an important assessment tool for the adequacy of medical education, which should result in a more focused approach in designing medical school curricula [25]. The Institute of Medicine has developed a broad range of core competencies for all health professionals [25]. The selected competencies are designed to address the knowledge, attitudes and skills that are required to ensure that physicians, or other health professionals, can care for the majority of people and the majority of problems that are brought into that specialty. For example, many of the competencies in obstetrics and gynecology address maternity care topics, whilst in surgery they focus on the most common problems that are referred to surgeons such as assessment of acute abdominal pain.

The recommended competencies are broadest for the primary care specialties, including family medicine, general internal medicine and general pediatrics, because the Institute of Medicine has suggested that $80 \%$ of all health care problems should be addressed in these specialty areas [25]. The broad scope of the recommended competencies explains the inclusion of basic history and physical examination skills, and the interpretation of ECGs. However, even though asthma and COPD are common problems in these specialties, the Institute of Medicine did not include spirometry performance and interpretation as a core competency or as a component of any of the case-based learning examples in the published documents [25].

There is no shortage of information regarding the teaching of basic spirometry skills. The characteristics of an adequate test have been delineated by several groups including the American Thoracic Society [26], the United States National Lung Health Program [27] and similar groups in the United Kingdom and other European nations. These characteristics include: an adequate effort to the "blow"'; absence of delayed start; no coughing or other disruptions in exhalation efforts; and sufficient duration of the exhalation to reach a plateau, usually four to six seconds. Simply allowing medical students to complete this testing on themselves and one or two of their colleagues, with observation by the instructors, is usually sufficient to demonstrate the technique and the necessity of actively encouraging participants to give of their best efforts. Students should use this portion of spirometry education to learn the basic characteristics of an acceptable test result.

Interpretation skills should include the ability to identify normal lung function, obstructive disease, reversibility of obstruction, and restriction. This assessment should begin by looking at expiratory curves or flow-volume loops in order to identify the common sail pattern of normal expiration, the scooped or ski-slope curves of obstruction, and the limited total volume of restrictive disease [28]. Since the most common curves produced by spirometry testing in primary care will be those associated with asthma and COPD, emphasis should be placed on obstructive patterns, with and without reversibility. The percentages of predicted forced expiratory volume in one and six seconds ( $\mathrm{FEV}_{1}$ and $\mathrm{FEV}_{6}$ respectively) and the forced vital capacity (FVC) are the most valuable spirometry results, are commonly used by physicians other than pulmonologists or allergists, and should therefore be the focus of early medical education.

Students should learn to recognize the most common obstructive patterns, and then should be exposed to other patterns that do not fit these models. The time required for this training should be minimal and may be associated with the enthusiasm with which medical students often approach hands-on learning. This education can provide the foundation for generalists who go on to perform spirometry in their offices. It should also be helpful for surgeons and other non-pulmonary specialists whose patients may happen to have asthma or COPD in addition to the problem that the specialist is addressing. 
Practising primary care physicians are beginning to realize the importance of office-based spirometry testing. Several completed projects and others now in progress confirm that general practitioners and family physicians can perform accurate office-based spirometry testing [3,4,29-33]. Most of the projects include training for physicians and their office staff on the correct procedure for spirometry testing and on the interpretation of results in the context of the patient's illness. These programs are useful for training physicians already in practice, but it would be far better to teach basic spirometry performance and interpretation during medical school and residency when students are learning to identify and treat asthma and COPD. Failure to include spirometry testing and interpretation in medical education appears to be a missed opportunity that requires immediate action.

In summary, spirometry is a diagnostic test which is applicable to large numbers of general practice patients who have illnesses that incur substantial morbidity and mortality. Spirometry skills are not routinely taught in U.S. or European medical schools, whereas other skills of similar importance such as ECG-interpretation are extensively covered. Instruction techniques for spirometry are well established, and in some ways acquisition of spirometry skills is simpler than learning to interpret ECGs. Increased use of spirometry in the primary care setting has the potential to improve patient care and to decrease morbidity.

\section{Recommendations}

Spirometry is a basic skill that physicians should acquire early in their education, preferably during medical school or residency. Influential institutions like the Institute of Medicine should recommend that spirometry be a core competency to be taught in all medical schools. Developers of medical school curricula should recognize the burden of asthma and COPD in the community and ensure that the practitioners they train are adequately equipped to care for those conditions properly. The medical community can no longer ignore a basic and easily performed diagnostic test for asthma, the most common chronic illness in children, and COPD, the fourth leading cause of death in adults.

\section{References}

[1] Ait-Khaled N, Enarson D, Bousquet J. Chronic respiratory diseases in developing countries: the burden and strategies for prevention and management. Bull World Health Organ 2001;79(10):971-9. ISSN 0042-9686.

[2] Morbidity and Mortality: 2004 Chart Book on Cardiovascular, Blood, and Lung Diseases. National Institutes of Health, National Heart, Lung and Blood Institute, May 2004. p. 5, http://www.nhlbi.nih.gov/resources/docs/cht-book.htm.

[3] Schermer TRJ, Folgering HTM, Bottema BJAM, Jacobs JE, van schayck $C P$, van Weel $C$. The value of spirometry for primary care: Asthma and COPD. Prim Care Resp J 2000;9:51-5.

[4] Schermer T, Jacobs A, Chavannes N, Hartman J, Folgering $H$, Bottema $B$, et al. Validity of spirometry in a general practice population of patients with chronic obstructive pulmonary disease (COPD). Thorax 2003;58:861-6.

[5] Eaton T, Withy S, Garrett JE, Mercer J, Whitlock RML, Rea $\mathrm{HH}$. Spirometry in primary care practice. The importance of quality assurance and the impact of spirometry workshops. Chest 1999;116:41-23.

[6] Rutten-van Molken MP, Postma MJ, Joore M, van Genugten ML, LeidlR, Jager JC. Current and future medical costs of asthma and chronic obstructive pulmonary disease in the Netherlands. Resp Med 1999;93:779-87.

[7] Tirimanna PRS, van Herwaarden CLA, van Schayck CP, et al. Prevalence of asthma and COPD in general practice in 1992: has it changed since 1977? Br J Gen Pract 1996;46:277-81.

[8] Van Weel C. Underdiagnosis of asthma and COPD: is the general practitioner to blame? Monaldi Arch Chest Dis 2002;57:65-8.

[9] Global Family Doctor - WONCA Online. Website of the World Organization of Family Doctors. http://www. globalfamilydoctor.com/ Date accessed: June 9, 2003.

[10] Global Initiative for Chronic Obstructive Lung Disease, www.goldcopd.com. Date accessed June 12, 2004.

[11] Practical Guide for the Diagnosis and Management of Asthma, NAEPP, NIH Publication 97-4053, October, 1997. p. 4, http://www.nhlbi.nih.gov/health/prof/lung/ asthma/practgde/practgde.pdf.

[12] Pocket Guide to Asthma Management and Prevention, Global Initiative for Asthma, p. 13, http://www. ginasthma.com/GINApocketguide04.pdf.

[13] The COPD Guidelines Group of the Standards of Care Committee of the BTS. BTS guidelines for the management of chronic obstructive pulmonary disease. Thorax 1997;52(Suppl. 5):S1-28.

[14] Korsten AMMH, van Schuyck CP. New International Primary Care Airways Guidelines (IPAG). Revue Francaise e' Allergologie et d'Immunologie Clinique 2003;43:246-8.

[15] International Primary Care Respiratory Group. www.ipcrg.org date updated: July 30, 2003; Date accessed: May 7, 2004.

[16] Suwabe A, Kanbe M. Investigation for clinical practice of pulmonary function tests in undergraduate medical education - results from the inquires to 91 medical institutes with the Department of Laboratory Medicines in Japan. Rhinsho Byori 2004;52(4):295-300.

[17] Pham HH, Simonson L, Elnicki DM, Fried LP, Goroll AH, Bass EB. Training U.S. medical students to care for the chronically ill. Acad Med 2004;72(1):32-40.

[18] Mandin H, Harasym P, Eagle C, Watanabe M. Developing a "clinical presentation" curriculum at the University of Calgary. Acad Med 1995;70(3):186-93.

[19] O'Connell MT, Pascoe JM. Undergraduate medical education for the 21st century: leadership and teamwork. Fam Med 2004;36(Suppl):S51-6.

[20] Rodenbaugh DW, Collins HL, Dicarlo SE. Spirometry: simulations of obstructive and restrictive lung diseases. Adv Physiol Educ 2002;26(1-4):222-3. 
[21] Ostrow DN, Craven N, Cherniack RM. Learning pulmonary function interpretation: deductive versus inductive methods. Am Rev Respir Dis 1975;112(1):89-92.

[22] Hatala RM, Brooks LR, Norman GR. Practice makes perfect: the critical role of mixed practice in the acquisition of ECG interpretation skills. Adv Health Sci Educ Theory Pract 2003;8(1):17-26.

[23] Hurst JW. Methods used to interpret the 12-lead electrocardiogram: pattern memorization versus the use of vector concepts. Clin Cardiol 2000;23(1):4-13.

[24] Nathanson LA, Safran C, McClennen S, Goldberger AL. ECG Wave-Maven: a self-assessment program for students and clinicians. Proc AMI Symp 2001:488-92.

[25] Greiner AC, Kneble E, editors. Health Professions Education: A Bridge to Quality. Washington, DC: National Academy Press; 2004.

[26] American Thoracic Society. Standardization of spirometry: 1994 update. Am J Respir Crit Care Med 1995;152:1107-36.

[27] Maclntyre NR. The American Association for Respiratory Care and the National Lung Health Education Program: assuring quality in spirometry. Respir Care 2004;49(6):587-8.
[28] Enright PL, Johnson LR, Connett JE, Voelker H, Buist AS. Spirometry in the Lung Health Study. 1. Methods and quality control. Am Rev Respir Dis 1991;143:121523.

[29] Wanger J, Irvin CG. Office spirometry: equipment selection and training of staff in the private practice setting. J Asthma 1997;34(2):93-104.

[30] Hepper NG, Drage CW, Davies SF, Rupp WM, LaMothe J, Schoenfelder PG, et al. Chronic obstructive pulmonary disease: a community-oriented program including professional education and screening by a voluntary health agency. Am Rev Respir Dis 1980;121(1):97-104.

[31] Ferguson GT, Enright PL, Buist AS, Higgins MW. Office spirometry for lung health assessment in adults: A consensus statement from the National Lung Health Education Program. Chest 2000;117(4):1146-61.

[32] Pulten RL, Teaching bedside incentive spirometry. Nursing 2003;33(8):24.

[33] Schermer T, Eaton T, Pauwels R, van Weel C. Spirometry in primary care: is it good enough to face demands like World COPD Day? Eur Respir J 2003;22:725-7.

Available online at www.sciencedirect.com

science $Q d$ Direct

\section{Available online at http://www.thepcrj.com}

